\title{
Os Desafios No Cotidiano De Estudantes Universitários Com Deficiência: Barreiras Ou Facilitadores?
}

\section{The Challenges In The Everyday Of University Students With Disabilities: Barriers Or Facilitators?}

Elenice Moreira Arrué, Taísa Gomes Ferreira (In memorian), Aline Sarturi Ponte, Miriam Cabrera

Como citar este artigo:

Arrué, E; Ferreira, T; Ponte, A; Delboni, M. Os Desafios No Cotidiano De Estudantes Universitários Com Deficiencia: Barreiras Ou Facilitadores? Revista Saúde (Sta. Maria). 2019; 45 (2).

\section{Autor correspondente: \\ Nome: Aline Sarturi Ponte Email: alinesarturi@hotmail.com Filiação Institucional: Doutoranda em Distúrbios da Comunicação Humana, Universidade Federal de Santa Maria Prédio do Centro de Ciências da Saúde - CCS, Anexo 26C, Departamento de Terapia Ocupacional. \\ Endereço para correspondência: Av. Roraima no 1000, Cidade Universitária, Bairro Camobi, Santa Maria - RS, CEP: $97105-900$. Email: andribas22@yahoo.com. br; Telefone para contato: (55) $99612-0320$.}

Data de Submissão:

25/06/2019

Data de aceite:

24/07/2019

Conflito de Interesse: Não há conflito de interesse

\section{(cc) $\mathrm{BY}-\mathrm{NC}-\mathrm{ND}$} \begin{abstract}
Corvelo Delboni
Tendo em vista o expressivo número de pessoas com alguma deficiência e o crescimento da população idosa faz-se necessário a realização de pesquisas que contemplem a necessidade das pessoas com deficiência, como o direito de ir e vir e de praticar a sua cidadania. Este estudo teve como objetivo realizar um levantamento dos acadêmicos ingressantes em uma Instituição de Ensino Superior - IES do Sul do Brasil pelas Ações Afirmativas B e identificar as barreiras arquitetônicas ou urbanísticas encontradas por estes. Caracteriza-se como um estudo quantitativo, realizado através de um levantamento de dados secundários do Núcleo de Acessibilidade da Instituição, no período de novembro de 2014. Foi realizada análise descritiva dos com o auxílio do Software Statistica 9. E a análise dos dados relacionados barreiras arquitetônicas e urbanísticas realizou-se um comparativo entre a realidade encontrada nas edificações e as exigências da NBR - 9050. No ano de 2013 ingressaram pelas Ações Afirmativas B 233 acadêmicos, deste total 155 estavam matriculados regularmente; a unidade universitária com o maior número de ingressantes foi o Centro de Ciências da Saúde - CCS com 42 acadêmicos; e curso de Medicina é o mais procurado pelos concorrentes (22 acadêmicos). Os facilitadores encontraram-se guias rebaixadas, rampas, barras de apoio, banheiros adaptados. Quanto as Barreiras calçadas sem guias rebaixadas, piso tátil colocado de forma inadequada, calçamento irregular, elevador antigo, escadas com degraus irregular e piso liso. Verificaram-se facilitadores além da diminuição das barreiras físicas até o local de um dos centros. Porém, percebe-se que muitas barreiras precisam ser extintas para o melhor desempenho ocupacional nas atividades de vida prática destes acadêmicos, pois estes obstáculos acabam gerando impedimentos como a dificuldade de acesso das pessoas com deficiência ou mobilidade reduzida.
\end{abstract}

Palavras-chave: Pessoas com Deficiência; Barreiras Arquitetônicas; Terapia Ocupacional.

\section{ABSTRACT}

In view of the significant number of people with disabilities and the growth of the elderly population, it is necessary to carry out research that addresses the needs of people with disabilities, such as the right to come and go and to practice their citizenship. This study aimed to carry out a survey of the students entering a Higher Education Institution - IES do Sul do Brasil for the Affirmative Actions B and to identify the architectural or urbanistic barriers encountered by them. It is characterized as a quantitative study, carried out through a secondary data survey of the Accessibility Center of the Institution, in the period of November 2014. A descriptive analysis was performed with the help of Software Statistica 9. And the analysis of data related barriers architectural and urban planning, a comparison was made between the reality found in the buildings and the requirements of the NBR-9050. In the year of 2013, 233 academic students joined the Affirmative Actions, of which 155 were enrolled regularly; the university unit with the largest number of participants was the Health Sciences Center - CCS with 42 academics; and medical course is the most sought after by competitors (22 academics). The facilitators found themselves recessed guides, ramps, grab bars, adapted toilets. As for sidewalk barriers without recessed guides, improperly placed tactile floor, uneven pavement, old elevator, stairs with uneven stairs and smooth floor. Facilitators were seen as well as the reduction of physical barriers to the site of one of the centers. However, it has been observed that many barriers need to be extinguished for the best occupational performance in the practical life activities of these academics, as these obstacles end up generating impediments such as the difficulty of access for people with disabilities or reduced mobility. 


\section{INTRODUÇÃO}

Mundialmente, pessoas com deficiência vêm conquistando seu espaço dentro da sociedade. A Declaração Universal dos Direitos Humanos ${ }^{1}$ ressalta que todos tem direito a educação, na legislação brasileira, a educação é um dos direitos sociais garantidos no Capítulo II, art. $6^{\circ}$ da Constituição Federal brasileira. No Capítulo III - Da Educação, da Cultura e do Desporto, este direito é reforçado pelo art. 205 a educação é "direito de todos e dever do Estado e da família, será promovida e incentivada com a colaboração da sociedade, visando ao pleno desenvolvimento da pessoa, seu preparo para o exercício da cidadania e sua qualificação para o trabalho"2:123.

A década de 1990 foi um período marcado pela criação de um grande percentual da legislação Federal, Estadual e Municipal brasileira, voltada a garantir os direitos das pessoas com deficiência e a diversidade como um todo ${ }^{3}$. As mudanças na área da educação foram impulsionadas pela Lei de Diretrizes e Bases - LDB - n. 9.394 de 20 de dezembro de 1996, este documento trata de mudanças no ambiente escolar para garantir o acesso desta população a educação4 .

Sendo assim, considerando os propósitos da LDB e a Constituição Federal brasileira a Lei n 13.146 de 6 de julho de 2015 em seu Capítulo II - Da Igualdade e da Não Discriminação, no art. $8^{0}$ responsabiliza o Estado, a sociedade e a família a garantir o direito a educação as pessoas com deficiência. No Capítulo IV - Do Direito à Educação, art. 27 assegura as pessoas com deficiência o acesso ao sistema educacional inclusivo em todos os níveis de ensino. Esta legislação ressalta que o direito a acessibilidade é "para todos os estudantes, trabalhadores da educação e demais integrantes da comunidade escolar às edificações, aos ambientes e às atividades concernentes a todas as modalidades, etapas e níveis de ensino"5:34.

Mas mesmo com tantos documentos legais que garante as pessoas com deficiência o direito a educação, esta população ainda encontra dificuldades para acessar todos os níveis de educação. As Instituições de Ensino Superior - IES têm disponibilizado as pessoas com deficiência ações para a efetivação do acesso do estudante ao ensino superior, são estas: bancas especializadas, Tradutores Intérpretes de Língua de Sinais - TILS, Software para leitura, provas ampliadas para pessoas com baixa visão e outros atendimentos especializados, para atender as pessoas com deficiência³.

Mas a inclusão das pessoas com deficiência em uma IES vai para além da sala de aula, estas dependem também das condições de acesso urbanísticas e arquitetônicas. A Organização das Nações Unidas garante a partir da Declaração Universal dos Direitos Humanos que "[...] todos têm o direito de participar livremente da vida cultural da comunidade, de fruir as artes e de participar do processo científico e de seus benefícios"1:s/p, sendo assim, é direito de todas as pessoas locomoverem-se livremente, ter acesso a educação, ao trabalho, moradia e lazer.

No Brasil, desde a Constituição Federal brasileira todos os cidadãos tiveram seus direitos garantidos independente 
de sua condição de saúde. Dentre as garantias encontramos no art. $5^{\circ}$ inciso XV o direito a livre locomoção, sendo assim, todo cidadão tem direito de ir e vir livremente nas ruas, nas praças, nos lugares públicos². Baseado nos princípios da segurança e autonomia a Política Nacional de Mobilidade Urbana - Lei nº 12.587 de 03 de janeiro de 2012 - reforça 0 direito a livre locomoção a todas as pessoas. Nesta política municípios com mais de 20.000 habitantes devem ter um Plano de Mobilidade Urbana e neste deve ser garantido acessibilidade a todas as pessoas com deficiência e restrição de mobilidade ${ }^{5}$.

A Lei n 13.146 de 6 de julho de 2015 dispõem em seu Capitulo I - Disposições Gerais - Art. $3^{\circ}$, inciso I conceitua acessibilidade como:

possibilidade e condição de alcance para utilização, com segurança e autonomia, de espaços, mobiliários, equipamentos urbanos, edificações, transportes, informação e comunicação, inclusive seus sistemas e tecnologias, bem como de outros serviços e instalações abertos ao público, de uso público ou privados de uso coletivo, tanto na zona urbana como na rural, por pessoa com deficiência ou com mobilidade reduzida:20.

Toda pessoa tem o direito de ir e vir, sendo de responsabilidade dos gestores públicos instituírem ações para inclusão, dentre as quais a criação de programas de gerenciamento da acessibilidade ${ }^{6}$. A ausência de infraestrutura e serviços adequados restringe a oportunidade de utilização da cidade para parte da população ${ }^{7}$.

Mas, mesmo com a garantia do direito ao acesso à educação, as pessoas com deficiência ainda encontram diversas barreiras para acessar todos os níveis de ensino, sendo as barreiras físicas e arquitetônicas as que mais comprometem este acesso. As barreiras físicas no ambiente natural podem obstruir ou impedir uma pessoa com deficiência de participar das atividades diárias, enquanto recursos construídos podem melhorar a acessibilidade e efetivar a sua participação.

A legislação brasileira conceitua barreiras como, quaisquer

entrave, obstáculo, atitude ou comportamento que limite ou impeça a participação social da pessoa, bem como o gozo, a fruição e o exercício de seus direitos à acessibilidade, à liberdade de movimento e de expressão, à comunicação, ao acesso à informação, à compreensão, à circulação com segurança, entre outros $5: 9$.

Estas são classificadas em seis tipos de barreiras, são elas: barreiras urbanísticas, arquitetônicas, de transportes, nas comunicações, atitudinais e as tecnológicas. Este estudo ocupa-se em discutir as barreiras urbanísticas "existentes nas vias e nos espaços públicos e privados abertos ao público ou de uso coletivo" 5:10 e as barreiras arquitetônicas "existentes nos edifícios públicos e privados" ${ }^{5: 10}$. Frente a estas reflexões, sente-se a necessidade de identificar como as barreiras arquitetônicas e urbanísticas podem dificultar aos acadêmicos com deficiência física, o acesso à Universidade, nos prédios, salas de aulas, bibliotecas, banheiros e ao restaurante universitário.

Este estudo teve como objetivo realizar um levantamento dos acadêmicos ingressantes em uma IES do Sul do Brasil pelas Ações Afirmativas B e identificar as barreiras arquitetônicas ou urbanísticas encontradas por estes. 


\section{MÉTODOS}

Este estudo caracteriza-se como um estudo quantitativo. Trata-se de um levantamento de dados secundários do Núcleo de Acessibilidade de uma IES pública do Sul do Brasil. Para a realização deste estudo foi solicitado a autorização da Instituição e posteriormente o estudo foi submetido à apreciação do Comitê de Ética em Pesquisa em Seres Humanos, da Instituição onde se realizou o estudo, sendo aprovado sob parecer número 222.242.

No momento em que foi realizada a pesquisa a IES envolvida neste estudo contava com uma população acadêmica de 29.700 alunos, incluindo os cursos de Educação a Distância (EaD). Esta Instituição distribui-se em 10 unidades universitárias, sendo estes: Centro de Artes e Letras (CAL), Centro de Ciências Naturais e Exatas (CCNE), Centro de Ciências Rurais (CCR), Centro de Ciência da Saúde (CCS), Centro de Ciências Sociais e Humanas (CCSH), Centro de Educação (CE), Centro de Educação Física e Desportos (CEFD), Centro de tecnologia (CT), Centro de Educação Superior Norte (CESNORS) Campus Frederico Westphalen - Palmeira das Missões, Unidade Descentralizada de Educação Superior da universidade em Silveira Martins (UDESSM).

A IES envolvida neste estudo criou no ano de 2007 a Resolução n. 011 de 03 de agosto de $2007^{9}$ e além desta, apoia-se também na Lei n. 12.711 de 29 de agosto de $2012^{10}$, ambas se referem ao programa de Ações Afirmativas instituídas na IES. A partir da Resolução n. 011 destinou-se 15\% das vagas para negros e pardos; $5 \%$ para pessoas com deficiência - chamada de Ação Afirmativa B, 20\% para escola pública, além de vagas para indígenas. Ambos os documentos citados são utilizados como base para construção deste estudo.

A Coleta de dados ocorreu em novembro de 2014. Esta apoia-se no levantamento dos dados secundários nos cadastros do Núcleo de Acessibilidade dos acadêmicos matriculados pelas Ações Afirmativas B em uma IES pública do interior do Rio Grande do Sul até o ano de 2013 e relaciona estes dados com as barreiras arquitetônicas e urbanísticas identificadas pela pesquisadora, segundo o que se propõe nas normativas técnicas de acessibilidade da Associação Brasileira de Normas Técnicas - ABNT pela Norma Brasileira Regulamentadora - NBR - 905011.

Durante o levantamento dos dados secundários foram coletadas informações referentes ao número total de acadêmicos com deficiência matriculados no ano de 2013, qual a unidade universitária e o curso que tem o maior número de matriculados, quais as deficiências dos acadêmicos, entre outros. Os dados secundários são definidos como as informações já produzidas que o investigador recolhe, ou seja, não há a influência do investigador sobre a fonte de informação ${ }^{12}$.

Os dados quantitativos foram analisados através de análise descritiva com o auxílio do Software Statistica 9. E para a análise dos dados sobre as barreiras arquitetônicas e urbanísticas foi realizado um comparativo entre a realidade encontrada nas edificações e as exigências da NBR - 905011.

\section{RESULTADOS E DISCUSSÃO}

Segundo os dados levantados na IES, no ano de 2013 estavam matriculados pelas Ações Afirmativas B 233 acadêmicos, destes 155 acadêmicos estavam matriculados regularmente. A unidade universitária com o maior quantitativo de acadêmicos ingressantes pelas Ações Afirmativas B da IES é o CCS com 42 acadêmicos, sendo que 0 curso de Medicina é o mais procurado pelos concorrentes, este curso tinha 22 acadêmicos matriculados no momento da realização deste estudo.

Quanto ao tipo de deficiência, pode-se observar que os acadêmicos ingressantes na IES possuem deficiência 
auditivas, físicas, intelectuais, visuais, mentais e intelectuais. Pode-se observar que a maioria dos acadêmicos tinham deficiências físicas, seguido dos acadêmicos que tinham deficiências auditivas, visuais, mentais e intelectuais (Tabela 1).

Destaca-se que no Brasil há inserção de 583 alunos matriculados com deficiência física em Universidades Federais, e 379 em Instituições privadas de ensino superior ${ }^{13}$. O Instituto Nacional de Estudos e Pesquisas Educacionais Anísio Teixeira (INEP)em 2013 esboçou dados da inserção de pessoas com deficiência no ensino superior no estado do Rio Grande do Sul, RS, totalizando 2.143 pessoas com deficiência. Destes 988 alunos com deficiência física, 491 com baixa visão e 300 com deficiência auditiva ${ }^{14}$.

A garantia do direito referente a ter acesso ao Ensino Superior é assegurado pela legislação brasileira. $O$ direito à educação é inalienável e universal, sendo também considerado um direito que viabiliza a realização de outros direitos, pois ele prepara as pessoas com deficiência para o trabalho e para a obtenção de renda que lhes garantam viver com independência e dignidade ${ }^{13}$.

Tabela 1 - Tipos de Deficiência Acadêmicos da IES.

\begin{tabular}{|c|c|c|c|c|c|c|c|c|c|c|}
\hline $\begin{array}{c}\text { Tipos de } \\
\text { Deficiência }\end{array}$ & CAL & CCNE & CCR & $\operatorname{ccs}$ & $\mathrm{CCSH}$ & $\mathrm{CE}$ & CEFD & CT & CESNORS & $\begin{array}{c}\text { Total por } \\
\text { Tipos de } \\
\text { Deficiência }\end{array}$ \\
\hline Física & 2 & 4. & 4 & 13 & 19 & 2 & & 9 & 5. & 58 \\
\hline Auditiva & 2 & 1 & 5 & 14 & 13 & 9 & 1 & 11 & & 56 \\
\hline Visual & 2 & 1 & 3 & 14 & 5 & 3 & & 3. & 2 & 33 \\
\hline Mental & & 2 & & 1 & & & 1 & 2 & & 6 \\
\hline $\begin{array}{l}\text { Intelectual } \\
\text { Total de }\end{array}$ & & & & & 1 & & & & 1 & 2 \\
\hline $\begin{array}{l}\text { acadêmicos } \\
\text { por Unidade } \\
\text { Universitária }\end{array}$ & 6 & 8 & 12 & 42 & 38 & 14 & 2 & 25 & 8 & 155 \\
\hline
\end{tabular}

Verifica-se o grande índice de abandono, 53 (23\%) acadêmicos abandonaram os cursos, 14 (6\%) acadêmicos cancelaram, 7 (3\%) fizeram transferência e 7 (3\%) formaram-se (Figura 1). Mesmo a legislação brasileira dispondo de uma grande quantidade de documentos que garantem o acesso das pessoas com deficiência a educação e dos esforços das IES para garantir a permanência destes acadêmicos, "muitos ingressam e não conseguem prosseguir por falta de condições de acessibilidade"3:192. 
Figura 1 - Situação dos acadêmicos ingressantes pela Ação Afirmativa B.

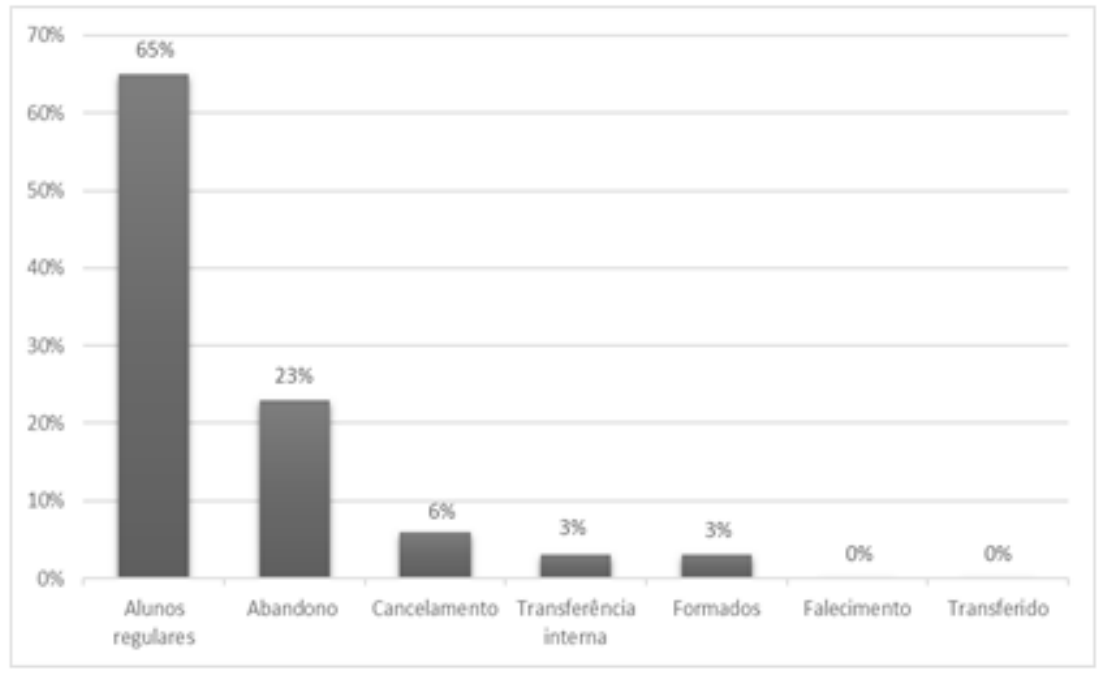

Fonte: Elaborado pelas autoras a partir dos dados fornecidos pelo Núcleo de Acessibilidade da UFSM.

Os acadêmicos matriculados pela Ação Afirmativa B, contam, desde o ano de 2007, com um suporte disponibilizado pelo Núcleo de Acessibilidade juntamente de uma Comissão de Acessibilidade, constituído através do Programa de Acessibilidade na Educação Superior (Incluir), este busca propor ações que garantam o acesso das pessoas com deficiência às Instituições Federais de Ensino Superior - IFES ${ }^{15}$. O Núcleo de Acessibilidade auxilia os acadêmicos matriculados na Instituição pela Ação Afirmativa $B$, quando estes deparam-se com alguma barreira arquitetônica dentro da IES. São competências do Núcleo de Acessibilidade,

Orientação para adequação frente às barreiras: pedagógicas, edificações, urbanísticas, transporte, informação e comunicação; Orientações à comunidade universitária a tecnologias e equipamentos especializados indicados às necessidades educacionais especiais; Esclarecimentos em relação à legislação brasileira referente às necessidades educacionais especiais; e Assessoria à comunidade universitária nas questões que envolvem acessibilidade ${ }^{16: s / p}$.

Neste espaço os acadêmicos encontram respaldo pós-seleção na universidade e aporte para reivindicar o que a legislação brasileira garante para a eliminação de barreiras de acesso ao campus ${ }^{16}$.

Quando a avaliação de acessibilidade, optou-se por realizar está no CCS, pois este é o centro que concentra o maior número de acadêmicos ingressantes pela Ação Afirmativa B, este tem quadro andares e foi criado em 1970. Foi realizado no local a identificação dos facilitadores e barreiras arquitetônicas e urbanísticas. No entorno do prédio, alguns dos facilitadores encontrados foram guias rebaixadas, rampas de acesso ao prédio e banheiros adaptados em todos os andares, tornando possível o acesso das pessoas com deficiência. (Figura 2).

Quando as barreiras no entorno do prédio, foram encontradas calçadas com o piso irregular e uma delas não apresentava guia rebaixada. 0 calçamento irregular e a falta da guia rebaixada dificultam o acesso ao prédio e exige que a pessoa que utiliza cadeira de rodas trafegue pela rua asfaltada, dividindo espaço com os carros. Observou-se durante a análise que algumas calçadas têm piso tátil para auxiliar na locomoção de deficientes visuais, mas a colocação deste está inadequada, pois em alguns pontos o piso não tem sequência, podendo causar confusão e/ou um acidente a pessoa com deficiência visual, caracterizando-se como uma barreira (Figura 2).

Outra barreira de acesso encontrada é o elevador, por ser um equipamento antigo, mesmo passando por 
manutenções, as vezes estraga e fica algum tempo interditado, o que acaba dificultando o acesso das pessoas com deficiência física aos andares superiores do CCS. A escada também apresenta algumas barreiras, o piso que compõe a estrutura da mesma é liso, esta não tem fitas antiderrapantes e nem fitas de sinalização, outra barreira encontrada é o espaçamento entre um degrau e outro e a diferença apresentada na altura dos mesmos. Esta barreira pode causar quedas/acidentes as pessoas que circulam por este espaço (Figura 2).

Figura 2 - Facilitadores e Barreiras encontrados pelas pessoas com deficiência no prédio do CCS.

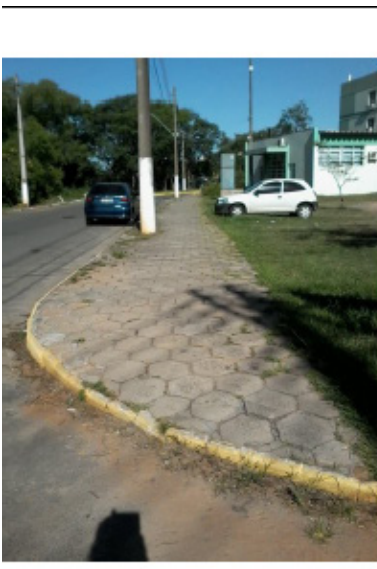

Sem guia rebaixada

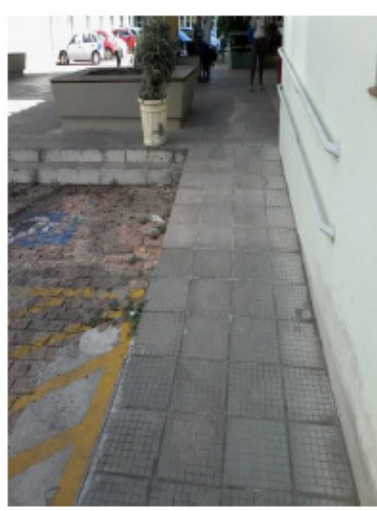

Barras de Apoio

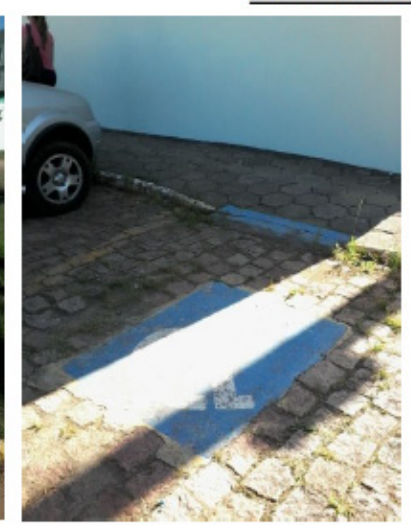

Guia Rebaixada

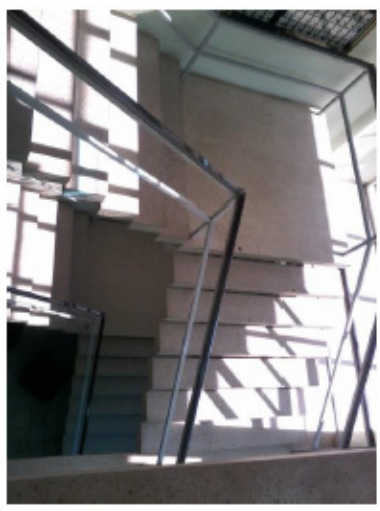

Escadas Internas

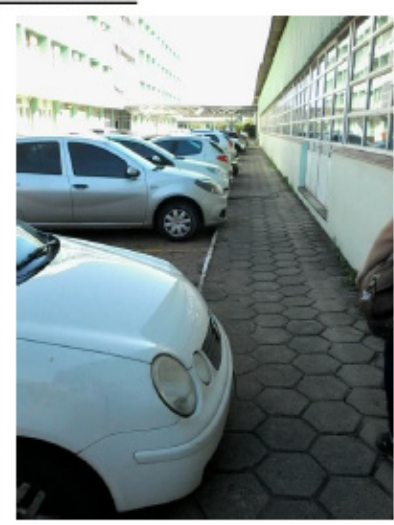

Acesso aos Prédios

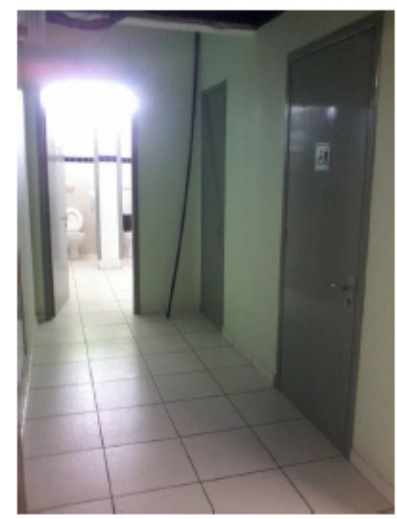

Banheiro Masculino

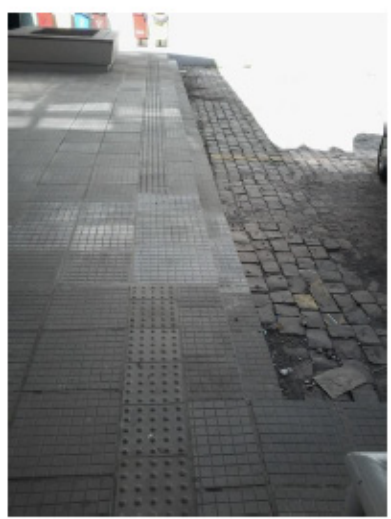

Piso Tátil

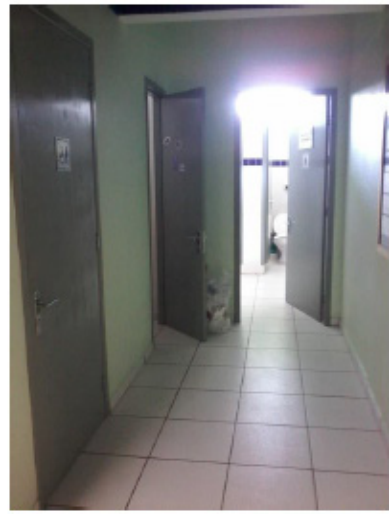

Banheiro Feminino

Fonte: Arquivo pessoal em 18/11/14

A eliminação destas barreiras nos espaços de ensino é garantida no art. $2^{\circ}$ da Portaria $n^{0} 3.284$ de 07 de novembro de 2003, estabelece "os requisitos de acessibilidade, tomando-se como referência a Norma Brasil 9050, da Associação Brasileira de Normas Técnicas (ABNT), que trata da acessibilidade de pessoas portadoras de deficiências a edificações, espaço, mobiliário e equipamentos urbanos"17:s/p.

Mas a eliminação de barreiras vai para além dos espaços de ensino, pois a locomoção dos acadêmicos não se restringe somente ao espaço da IES, este percorre um trajeto da sua casa até a Instituição e as barreiras ou facilitadores encontrados neste caminho também podem influenciar na permanecia dos acadêmicos na Universidade. Sabe-se que 0 ambiente influencia o comportamento e proporciona o contexto no qual todos os papéis são desempenhados. Na Terapia Ocupacional, o ambiente é amplamente definido como possuindo dimensões físicas, sociais, culturais, organizacionais e institucionais. Essas dimensões interagem umas com as outras e são difíceis de ser separadas; ou seja, elas são tidas como interdependentes ${ }^{17}$.

Deste modo, quando se pensa em acessibilidade, inclui-se a análise do trajeto que o acadêmico percorre para 
chegar até a Universidade. O que é uma rotina comum aos demais cidadãos, para as pessoas com deficiência há outra forma de se organizar para acessar e estar na Universidade. Portanto, entende-se que é necessária uma compreensão sobre o entorno urbano onde se insere esta Universidade.

A cidade de Santa Maria foi fundada em 17 de maio de 1858 (160 anos) e assim como na fundação da Universidade (14 de dezembro de 1960), a cidade também foi construída de acordo com as propostas de urbanização da época e que dificulta a locomoção de pessoas com deficiência na atualidade. Interferindo na autonomia do sujeito, ou seja, o individuo não possui total independência para circular dentro da cidade devido às barreiras arquitetônicas dentre outras. Ocorre que devido mesmo à acessibilidade estabelecida em lei, há dificuldade em materializar-se no meio urbano e isto afeta a qualidade de vida das pessoas, interferindo na rotina destes indivíduos principalmente os universitários que necessitam do meio de transporte para chegar até a instituição.

Conforme dados do Instituto Brasileiro de Geografia e Estatística - IBGE - Censo $2010^{13}$ o percentual de rampa de acessibilidade no entorno de domicílios permanentes urbanos encontra-se num percentual baixo (Figura 3).

Figura 3 - Percentual de domicílios particulares permanentes urbanos, segundo as características do entorno dos domicílios - Brasil - 2010.

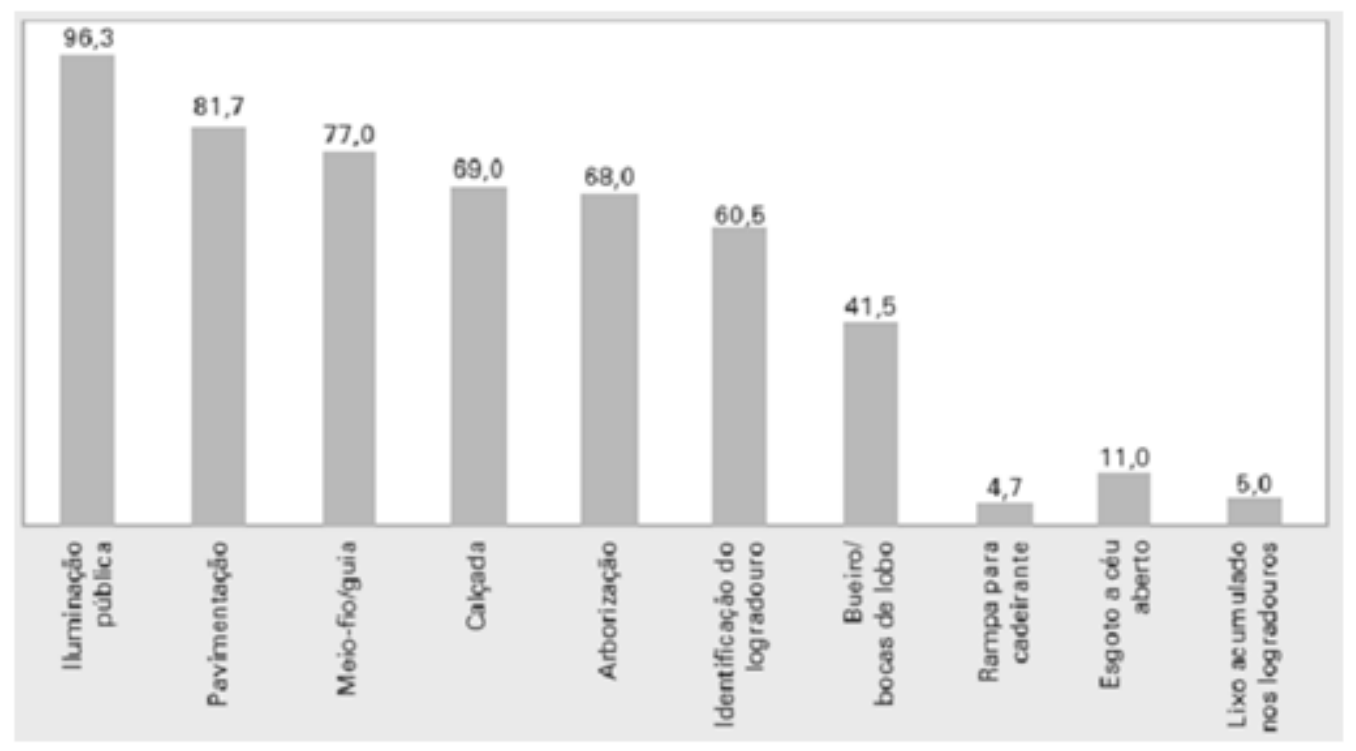

Fonte: Instituto Brasileiro de Geografia e Estatística - IBGE - Censo Brasileiro de 2010.

O declínio nos paralelepípedos é um problema existente em muitas ruas da cidade, este acaba interferindo na locomoção das pessoas com deficiência. Emmel, Gomese Bauab ${ }^{19}$ apontam a necessidade da redução das barreiras arquitetônicas para promover à integração de pessoas com deficiência em todos os ambientes. Estes demonstram que na presença de barreiras a qualidade dos serviços prestados está comprometida e a legislação brasileira está desrespeitada, sendo necessário então, reconhecer os direitos legítimos e legais da acessibilidade e integração social das pessoas e promover mudanças. Sendo assim, torna-se relevante refletir que é de responsabilidade do município diminuir as barreiras para as pessoas com deficiência, pois estas interferem na autonomia e limitam o direito de locomoção desta população.

Ao analisar os dados de 2010 do Instituto Brasileiro de Geografia e Estatística ${ }^{13}$ pode-se perceber que em 2010 no Brasil tinham 45.606 .048 de pessoas com deficiência, este total representava 23,9\% da população total do Brasil. Dentre as deficiências, a visual afeta o maior número $18,6 \%$ da população brasileira, deficiência motora $7 \%$ da população, deficiência auditiva $5,1 \%$ e deficiência mental ou intelectual em 1,4\%. Ao verificar os dados do município de 
Santa Maria pode-se observar a prevalência da deficiência visual (Tabela 2). De acordo com o Decreto n. ${ }^{0} 5.296$, de 02 de dezembro de $2004^{20}$ a pessoa é considerada deficiente quando possuir uma limitação ou incapacidade que afete 0 seu desempenho, conforme art. $5^{\circ}$.

Tabela 2 - Tipos de Deficiências no País, Estado e Município.

\begin{tabular}{lcccc}
\hline & Deficiência & Deficiência & Deficiência & Deficiência \\
& Auditiva & Mental/Intelectual & Motora & Visual \\
\hline Brasil & 9.717 .318 & 2.611 .536 & 13.265 .599 & 35.774 .392 \\
Rio Grande do Sul & 617.244 & 162.792 & 818.451 & 1.900 .633 \\
Santa Maria & 14.439 & 3.874 & 19.770 & 37.864 \\
População (\%) & 5,1 & 1,4 & 7 & 18,6 \\
\hline
\end{tabular}

Fonte: Instituto Brasileiro de Geografia e Estatística - IBGE, Censo Demográfico 2010.

O maior número de pessoas com deficiência encontra-se na região Nordeste do Brasil, com 14.133.713 habitantes, porém o sul do país onde há a menor prevalência esse quantitativo é de 6.164.158 pessoas. Conforme IBGE $^{12}$, comparando os dados do Censo de 2000 e de 2010, observou-se que a taxa de analfabetismo para a população com deficiência caiu de $13,6 \%$ para $9,5 \%$ na década. A queda foi mais acentuada na população feminina, que caiu de $13,5 \%$ para $9,3 \%$, enquanto que para a população masculina a taxa caiu de $13,8 \%$ para $9,9 \%$.

A diminuição do analfabetismo de pessoas com deficiência se dá através de programas criados junto ao governo federal, com leis garantindo vagas de empregos, escolaridade, criando uma maior circulação desta população na sociedade. O programa do governo federal - Viver sem Limites - de Decreto $n^{0} 7.612$, de 17 de novembro de 2011, no art $3^{\circ}$, parágrafo I garante que o sistema educacional brasileiro tem que ser inclusivo ${ }^{5}$. Deste modo, a legislação brasileira, garante que toda pessoa, incluindo aquelas que apresentam deficiências, têm direito ao acesso à educação, à saúde, ao lazer e ao trabalho. Desta forma, as pessoas devem ser percebidas com igualdade, implicando assim no reconhecimento e atendimento de suas necessidades especificas ${ }^{21}$.

Frente a realidade discutida neste estudo é mister que os terapeutas ocupacionais estejam cientes e responsivos aos conceitos do movimento de direito das pessoas com deficiência e a filosofia subjacente de vida independente, como algo que não trata do comprometimento da pessoa, mas o direito deste às oportunidades na sociedade e da necessidade de criar ambientes e modificar sistemas, para dar suporte a esses direitos ${ }^{22}$.

A despeito de todas as garantias por Leis, as pessoas com deficiência são tolhidas no que se refere à plena participação social e do exercício de sua cidadania em virtude das barreiras físicas e atitudinais encontradas no contexto brasileiro. A efetivação das Políticas Federais também encontra barreiras para se consolidarem nos municípios. Assim, pessoas com deficiência encontram dificuldades em realizar deslocamentos simples e garantidos aos demais nas cidades e nos espaços públicos tais como escolas, bancos, Unidades de Saúde e Universidades, impossibilitando o que se reconhece como Mobilidade Urbana para acessos de bens e serviços.

\section{CONCLUSÃO}

É inegável a necessidade de adotarmos posturas e programas de inclusão para garantir este direito as pessoas 
com deficiência; contudo, devemos lembrar que inclusão social extrapola essa dimensão, abrangendo o âmbito social, cultural e econômico e, em regra geral, uma gama muito mais variada de pessoas e segmentos sociais.

Pode-se observar pelos dados apresentados neste estudo um aumento de pessoas com deficiência nas IES, devido principalmente, ao que asseguram as Leis regulamentadoras do Governo Federal dos últimos anos. Desde 2007, as Universidade têm recebido muitos acadêmicos com deficiência.

Verificaram-se facilitadores além da diminuição das barreiras físicas até o local de um dos centros. Porém, percebe-se que muitas barreiras precisam ser extintas para o melhor desempenho ocupacional das pessoas com ou sem deficiência. A acessibilidade mostra-se de grande importância para a inclusão social, pois pessoas com deficiência ou com mobilidade reduzida necessitam de locais acessíveis para que possam circular livremente. A locomoção é uma forma de inclusão social e deve ser garantida para todos e em todos os ambientes públicos e/ou privados. Aacessibilidade é garantida pela NBR-9050 que dispõem de critérios e parâmetros técnicos para normalização de ambientes.

Embora existam as Normas da ABNT que regularizam os padrões de acessibilidade, estes nem sempre são seguidos corretamente. Esta norma é de domínio público e acessível a todos, mas alguns profissionais desconhecem a sua existência e acabam realizando adaptações incorretas que podem causar transtornos como: insegurança, dificuldade no acesso e transferência, alguns acidentes, entre outros. Em muitos locais existem barras de apoio instaladas inadequadamente e o espaço é limitado impossibilitando aos usuários que necessitam fazer o uso destes recursos. Desta forma, a inexistência ou má adequação das formas de acesso a locais de uso comum dificultam ainda mais o processo de inclusão social de pessoas com deficiência e/ou mobilidade reduzida.

O Núcleo de Acessibilidade da Instituição de ensino respalda todos os acadêmicos que ingressam pelas Ação Afirmativa $B$ na mesma. As ações desenvolvidas por este têm o objetivo dar condições para o acadêmico permanecer na Universidade de proporcionar aos mesmos uma formação igualitária. No entanto, observou-se que ainda existe um caminho logo a se percorrer, pois, apesar da entrada para a Universidade estar garantida pelo Estado, a permanência destes acadêmicos nas Universidade ainda deixa a desejar.

Sugere-se que outros estudos sejam realizados com essa temática a fim de serem produzidas mais evidências acerca do assunto abordado por este estudo.

\section{REFERÊNCIAS}

1 ONU. Declaração Universal dos Direitos Humanos. 1948. Disponível em: https://www.unicef.org/brazil/pt/ resources_10133.htm. Acessado em: 22 de agosto de 2018.

2 Brasil. Constituição da República Federativa do Brasil. Brasília, DF: Senado, 1988.

3 Mendes HSF, Bastos CCBC. Um estudo sobre a realidade da inclusão de pessoas com deficiência na educação superior no Paraná. Revista Educação Especial. Santa Maria. 2016; 29(54):189-202.

4 Brasil. Lei de Diretrizes e Bases - LDB. 1996. Disponível em: http://www.planalto.gov.br/CCIVIL_03/Leis/L9394.htm. Acessado em: 25 de agosto de 2018.

5 Brasil. Lei n0 13.146 de 06 de junho de 2015. Estatuto da pessoa com deficiência. Brasília: Senado Federal, Coordenação de Edições Técnicas, 2015.

6 Ferreira EFB, Folha OAAC, Tobias MSG. Avaliação da percepção sobre o ambiente de circulação: a acessibilidade 
centrada no usuário. Cadernos de Terapia Ocupacional da UFSCar, São Carlos, 2013; 21(1):25-33.

7 Brasil. Decreto Legislativo n 186, de 09 de julho de 2008. Convenção sobre os Direitos das Pessoas com Deficiência: Protocolo Facultativo à Convenção sobre os Direitos das Pessoas com Deficiência. Brasília: Secretaria de Direitos Humanos, 2008.

8 Trombly CA, Radomski MV. Terapia Ocupacional para Disfunções Físicas. 5.ed. São Paulo: Santos Editora, 2005.

9 Universidade Federal de Santa Maria - UFSM. Resolução N. 011 de 03 de agosto de 2007. Institui, na Universidade Federal de Santa Maria, o Programa de Ações Afirmativas de Inclusão Racial e Social. Disponível em: http://w3.ufsm.br/ afirme/images/011-07.pdf. Acessado em 20 de agosto de 2018.

10 Brasil. Lei n. 12.711 de 29 de agosto de 2012. Dispõe sobre o ingresso nas universidades federais e nas instituições federais de ensino técnico de nível médio e dá outras providências. 2012.

11 Associação Brasileira de Normas Técnicas - ABNT. Norma Brasileira Regulamentadora - NBR - 9050. $3^{\circ}$ ed. 2015. Disponível em: http://www.ufpb.br/cia/contents/manuais/abnt-nbr9050-edicao-2015.pdf. Acessado em 20 de agosto de 2108.

12 Coutinho C, Sousa A, Dias A, Bessa F, Ferreira M, Vieira S. Investigação-acção: metodologia preferencial nas práticas educativas. Psicologia, Educação e Cultura. Vila Nova de Gaia Porto. 2009; 13(2):355-80.

13 Instituto Brasileiro de Geografia e Estatística - IBGE, Censo Brasileiro de 2010. Disponível em: http://www.ibge.gov. br/home/default.php. Acessado em: 20 de maio de 2014.

14 Instituto Nacional de Estudos e Pesquisas Educacionais Anísio Teixeira - INEP. Dados Gerais 2013. Disponível em: http://portal.inep.gov.br/superior-censosuperior-sinopse. Acessado em: 27 de outubro de 2014.

15 Brasil. Programa Incluir - Acessibilidade na Educação Superior SECADI/SESu. Ministério da Educação. Brasília, 2013.

16 Universidade Federal de Santa Maria - UFSM. Núcleo de Acessibilidade. Disponível em: http://w3.ufsm.br/ acessibilidade/. Acesso em: 20 de maio de 2014.

17 Brasil. Portaria n 3.284, de 07 de novembro de 2003. Disponível em: portal.mec.gov.br_seesp_arquivos_pdf_port3284. pdf. Acesso em: 24 de maio de 2014.

18 Law M, Cooper B. Strong S, Stewart D, Rigby P, Letts, L. The person - Envoronmen t-Occupation Model: Transactive Approach to Occupational Performance. Canadian Journal of Occupational Therapy, 1996.

19 Emmel MLG, Gomes G, Bauab JP. Universidade com Acessibilidade: Eliminando Barreiras e Promovendo a Inclusão em uma Universidade Pública Brasileira. Revista Brasileira de Ciência da Saúde. Paraíba. 2010; 14(1):7-20.

20 Brasil. Decreto n 5.296 , de 02 de dezembro de 2004. Disponível em: http://www.planalto.gov.br/ccivil_03/_ato20042006/2004/decreto/d5296.htm. Acesso em: 27/06/2014

21 Andrade MAS, Pacheco ML, Farias SSP. Pessoas com deficiência rumo ao processo de inclusão na educação superior. Conquer. Barreiras. 2006; 1(1): 1-5.

22 Crepeau, E. B.; Cohn, E. S.; Schell, B. A. B. Willard \& Spackman - Terapia Ocupacional. 11.ed. Rio de Janeiro: Guanabara Koogan, 2011. 